\title{
General Discussion to Papers of Dr Carter, Dr Meyer et al., Dr Agerholm and Dr Chawla et al.
}

DR P. Dollfus In the ChaIR. Thank you very much for your papers, the papers are now open for discussion.

DR PARRISH (G.B.). I should like to ask Dr Meyer whether he has carried out any follow-up studies of the use of his Engen splints. When I was working in a tetraplegic unit in Canada in the early I96os and I arranged for my patients to be supplied with Rancho flexion-hinge splints and followed up the use of the splints for various activities over a period of about 2 years, I found that the number of activities when they used the splints gradually decreased. What appeared to be happening was the fingers were stiffening during this period and the patient was without the splint beginning to get a flexor hinge action and they were only putting the splints on for finer manipulative procedures. One of the things that I also noticed happening is, if a patient discontinued using the splint, the thumb tended to become more adducted and just before I left Canada we started to think in terms of providing a flexor-hinge splint with thumb opening device. I wondered whether Dr Engen had any experience of this sort of phenomena with the automatic flexor-hinge type hand-kinedesis hand occurring in his tetraplegic patients and secondly whether he had thought about thumb opening devices. It is quite easy to do this as an adaption to the splint.

DR R. D. Shrosbree (S. Africa). Actually we are now conducting a retrospect survey of the patients that we have supplied with these splints, I can't give you any figures, but I can give you the number of splints fitted. So far we've had I70 patients fitted with splints and the Engen wrist extension we've fitted 240. We prefer to fit bilaterally and I do agree with you that sometimes the patients do tend to not fit their splints for the grosser movements. We have the advantage of getting the patient in very early and we fit the splints as soon as possible so this may make a difference as I stressed in the paper.

DR Dollfuss. Can I ask Dr Carter if he has any comments to this question.

DR R. E. CarTer (U.S.A.). I can't predispose to speak for the great Engen whose office is down the hall from me. We also attempt to fit these as early as possible to assure the patients particularly when they are mobilised that there is function. There is hope there for progress and to give them something to do. My general impression with most of our youngsters, particularly in the late teens and early twenties, is that they will average a wearing time of about 8 to Io months and by that time they do have some of the stiffness and the habit pattern so that for the grosser movements they won't put them on, the females for cosmetics and the males for academics in pursuing the school and work. They will reserve them for that.

DR F. W. MeINecke (Germany). May I ask just one question to Dr Carter. The group with the vital capacity below and above rooo cc. Do you have any further details what the reasons may be for this, maybe age, maybe associated injuries?

DR CARTER. Most of these with few exceptions were quite young individuals, and if I recall correctly, I don't think there was a single case of unilateral diaphragmatic paralysis although some were weak and at possibly the $3-4$ level innervated by $\mathrm{C}_{3}$ alone.

DR C. Pool (Holland). I was impressed by the numbers Carter told us about $\mathrm{C}_{3}$ and above patients and he had five patients with a phrenic stimulator. I would like to ask him how long they survived and another question is if he could remove the tracheostomy.

DR Dollfus. I think the question was difficult to understand. Could you repeat the last phrase please? 
Dr C. Pool (Holland). I repeat the last question. He had five patients with phrenic stimulator. I was impressed by the number and I was asking how long they survived and if he could remove the tracheostomy.

DR CARTER (U.S.A.). Of the five patients, one is not surviving, it was a unilateral implant. He was an improper candidate to begin with because he had most of his innervation gone. It just happened to be the only chance the young lad had for survival and we tried it anyway. The others remain alive, three with no other form of mechanical ventilation, the other two in progress. The oldest is a $C_{I}$ injured in 1968 who was implanted in 1970 so she's been eight years. We do not maintain necessarily tracheotomies after the first few years, but a Plumb button after Dr Fred Plumb in the old polio days, which keeps the opening patent in case we need it for respiratory infection. I've not been quite courageous yet to close the tracheostomy.

Mr P. HARRIS (G.B.). Without going into semantics Mr Chairman I would ask Dr Agerholm how she is using the term handicap and I wonder about the term disability. I presume that these terms are not used synonomously and I just would like to ask.

DR M. AGERHolm (G.B.). I think this is a delightful question. Disability tends to be used in so many ways that I've rather abandoned it except for meaning and inability to do something, or difficulty of ability which of course semantically should be spelt dys. I have actually written the whole paper about the semantics because I think it is quite time we got it right, and as far as I'm concerned disability is something you can't do whether it is you can't ski or you walk or you can't see, not being able to see is also a handicap, so I think we must stick with the word handicap, meaning a disadvantage which is what comes out of sport, it comes out of the sixteenth century and is well established.

DR Dollfus. May I add to this that the World Health Organisation is suggesting the word incapacity so I do hope that some day we will all speak the same language.

DR H. FRANKEL (G.B.). I'd like to congratulate Dr Carter on his preparation and presentation of his paper, that's what we really appreciate. I'd like to ask him about the tracheotomies performed in his patients. There seem to be a large number both those with large and small vital capacities and they seem to stay in a long time. Could he explain the reason for this.

Dr CarTer (U.S.A.). Most of that is by virtue of the fact that we do very few of them. They arrive that way, and generally are done in an emergency panicked basis. We've had to revise a number, but by and large we do very few, I suppose we've done less than 3 to 5 per cent of those, but generally they are done in an emergency situation, when they hit the emergency room somebody puts in an intertrachial tube and then the subsequent tracheotomy.

DR J. EASTON (U.S.A.). I would like to ask Dr Carter whether any of his patients learned quaso-pharyngeal breathing in the acute stage just before they recovered respiratory function? 